Abstract P22 Table 1 Clinical characteristics of patients in DOIRT pathway

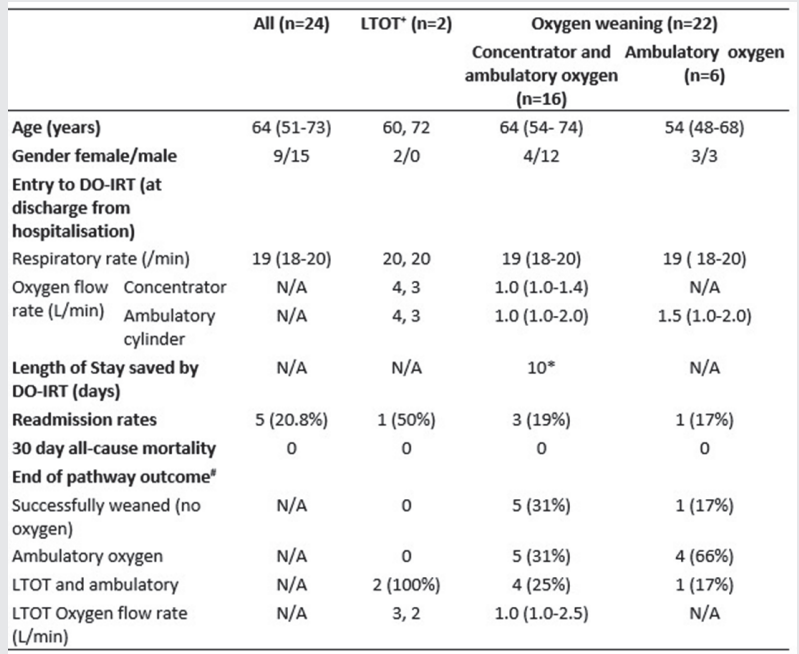

Data presented as median (IQR) or absolute numbers.

*hospital bed days saved (calculated for weaning cohort only). Represents duration from initiation of pathway to weaning to air at rest.

" 2 patients in concentrator and ambulatory cohort were readmitted and discharged without further referral to DO-IRT

Only 2 patents in cohort, thus all raw values presented

Majority of declined referrals (55\%) were patients who were above target saturations on oxygen and were supported to wean to air by IRT as inpatients. Duration on DO-IRT pathway was mean (SD) 16.3(7.2) days; median (IQR) length of stay saved for the oxygen weaning cohort were 9 (7-13) days. All-cause 30-day mortality and readmission rates on DO-IRT were $0 \%$ and $21 \%$ respectively. $14(58 \%)$ patients completed the satisfaction survey; $14(100 \%)$ reported confidence in their care and were 'extremely likely' to recommend DO-IRT.

Discussion Early supported discharge with home oxygen weaning for SARS-CoV2 pneumonia patients is feasible, safe and well-received by patients. Integrated respiratory teams with specialist oxygen expertise can make a valuable contribution to supporting acute medical flow. Future studies should investigate the feasibility of supported early discharge pathways with domiciliary oxygen in other conditions.

\section{P23 IMPLEMENTING A DAILY VIRTUAL COVID-19 MULTI- DISCIPLINARY TEAM MEETING IN SECONDARY CARE}

${ }^{1} \mathrm{JA}$ Wingfield Digby, ${ }^{2} \mathrm{H}$ Petty, ${ }^{2} \mathrm{~S}$ Brij, ${ }^{2} \mathrm{~J}$ Bright, ${ }^{2} \mathrm{~K}$ Irion, ${ }^{2} \mathrm{~W}$ Khan. ${ }^{1}$ University of Manchester, Manchester, UK; ${ }^{2}$ Manchester Royal Infirmary, Manchester, UK

\subsection{6/thorax-2021-BTSabstracts. 133}

Introduction In the UK, over 450, 000 people have been admitted to hospital with COVID-19, but co-ordinated MDT meetings to discuss cases, with combined respiratory, radiology and microbiology input have not been widely adopted, despite increased use of virtual MDT platforms in other specialties. This is surprising, given at times there is both diagnostic uncertainty, with low sensitivity of both nasal (63\%) and throat (32\%) COVID-19 RT-PCR tests and nuance around treatment decisions in these patients.

Aims and Methods We conducted a review of a virtual MDT (vMDT) set up and delivered daily (including weekends) over Microsoft teams to discuss management of inpatient COVID-

\begin{tabular}{|c|c|c|}
\hline Radiological Code $(n=200)$ & $\begin{array}{l}\text { Positive COVID-19 } \\
\text { RT-PCR } \\
(n=162,81 \%)\end{array}$ & $\begin{array}{l}\text { Negative COVID- } \\
19 \text { RT-PCR } \\
(\mathrm{n}=38,19 \%)\end{array}$ \\
\hline $\begin{array}{l}\text { CVCXO } \\
\text { (Normal appearances) }\end{array}$ & $3(1.5 \%)$ & $6(3 \%)$ \\
\hline $\begin{array}{l}\text { CVCX1 } \\
\text { (Classical/Probable COVID-19) }\end{array}$ & $103(51.5 \%)$ & $8(4 \%)$ \\
\hline $\begin{array}{l}\text { CVCX2 } \\
\text { (Non-classical/intermediate appearances) }\end{array}$ & $51(25.5 \%)$ & $19(9.5 \%)$ \\
\hline $\begin{array}{l}\text { CVCX3 } \\
\text { (Atypical - pleural disease/pulmonary } \\
\text { oedema/lobar consolidation) }\end{array}$ & $5(2.5 \%)$ & $5(2.5 \%)$ \\
\hline
\end{tabular}

19 from September 2020 to February 2021 (1012 patients, mean 8.5 cases/meeting). We conducted a retrospective case note analysis of 210 subjects, recording the RT-PCR result, radiological appearances (BSTI criteria) and decisions regarding investigation for VTE. Alongside this we conducted a qualitative survey (0-10 satisfaction) of 20 members regularly attending MDT members.

Results Attendance ranged from 5-15 people and always included a respiratory and radiology consultant and microbiology/virology registrar. Of the 200 MDT cases reviewed $(n=10$ excluded due to inadequate CXR or missing PCR), mean age was 64 years old, 66\% were male, 47\% BAME ,median LOS was 7 days and inpatient mortality was 41/200 (19\%). Over half of cases $(54.5 \%)$ had both a positive RT-PCR and classic CXR appearances of COVID-19, but $\mathrm{n}=5$ (2.5\%) had atypical features alongside a positive PCR, warranting discussion and consideration of dual pathology (TB/lung cancer/suspected phrenic nerve palsy all suggested). A significant proportion of patients with a negative RT-PCR, $n=8 / 38(21 \%)$ had radiological appearances that were classical of COVID-19 pneumonitis, prompting appropriate treatment and ward triage (avoiding hospital spread). CTPA was suggested in 16/200 $(8 \%)$ of patients' and confirmed PE in 5/16 scans. Of those surveyed, $>75 \%$ felt that their knowledge of anticoagulation (prophylaxis and treatment) in patients with COVID-19 improved and over $50 \%$ of junior doctors' submitted postMDT work based assessments.

Conclusion The COVID-19 vMDT helped with diagnosis and management of patients during the SARS-CoV-2 pandemic, whilst simultaneously providing education to health care professionals.

\section{P24 COVID-19 ADVANCED RESPIRATORY PHYSIOLOGY (CARP) WEARABLE RESPIRATORY MONITORING: EARLY INSIGHTS}

${ }^{1} \mathrm{SBH}$ Lua, ${ }^{1} \mathrm{D}$ Lowe, ${ }^{1} \mathrm{~A}$ Taylor, ${ }^{1} \mathrm{M}$ Sim, ${ }^{2} \mathrm{~B}$ Henderson, ${ }^{2} \mathrm{C}$ Trueman, ${ }^{2} \mathrm{O}$ Meredith, ${ }^{3} \mathrm{~S}$ Burns, ${ }^{3} \mathrm{P}$ McGuinness, ${ }^{1} \mathrm{C}$ Carlin. ${ }^{1}$ Respiratory Department, NHS Greater Glasgow and Clyde, Glasgow, UK; ${ }^{2}$ Altair Medical, Lanarkshire, UK; ${ }^{3}$ StormID, Edinburgh, UK

\subsection{6/thorax-2021-BTSabstracts.134}

Background Covid-19 presents an urgent need to monitor large number of patients with respiratory failure. Respiratory rate (RR) monitoring can predict deterioration but clinicianbased measurements are intermittent, often inaccurate, and frequency of measurements are dependent on level of care 